\title{
Phorbol myristate acetate suppresses breast cancer cell growth via down-regulation of P-Rex1 expression
}

\section{Dear Editor,}

P-Rex1 is a Rac-selective guanine nucleotide exchange factor (GEF) that is synergistically activated by G-protein coupled receptors and receptor tyrosine kinases (Welch et al., 2002). We previously reported that aberrantly upregulated P-Rex1 promotes prostate cancer metastasis by activating Rac1 signals (Qin et al., 2009). P-Rex1 is also highly overexpressed in estrogen receptor-positive and ErbB2-overexpressing human luminal breast tumors, which correlates with the aggressiveness of human breast cancer and poor outcome in breast cancer patients (Montero et al., 2011; Sosa et al., 2010). Silence of endogenous P-Rex1 blocks breast cancer cell proliferation, tumorigenesis, and motility (Montero et al., 2011; Sosa et al., 2010). Therefore, $\mathrm{P}-\mathrm{Rex} 1$ is an important mediator in cancer progression and could be a potential therapeutic target.

Protein kinase $C(P K C)$, a family of serine-threonine kinases, has been implicated in breast cancer progression (Urtreger et al., 2012). PKC isozymes are classified into conventional ( $\alpha, \beta$, and $\gamma)$, novel $(\delta, \varepsilon, \eta$, and $\theta)$, and atypical $(\zeta$ and $\lambda$ ) PKCs. Expression profiles of PKC isoforms vary among different breast cancer cell lines (Urtreger et al., 2012). Phorbol 12-myristate 13-acetate (PMA), a structural homolog of diacylglycerol (DAG), activates conventional and novel PKCs. PMA treatment induces breast cancer cell growth arrest via sustained up-regulation of the cell-cycle inhibitor p21 (WAF1/CIP1) (Barboule et al., 1999; Fortino et al., 2008). Interestingly, Rac1 was reported to be overexpressed or hyperactive in breast cancer tissues (Schnelzer et al., 2000) and hyperactivity of Rac1 suppressed p21 (WAF1/CIP1) expression in cancer cells (Knight-Krajewski et al., 2004). Since P-Rex1 functions as a Rac1 activator in cancer cells (Qin et al., 2009; Sosa et al., 2010), the purpose of the present study was to determine the role of P-Rex1 in PMA inhibition of breast cancer cell growth.

Both MCF-7 and BT-474 cell lines, derived from human luminal breast cancers, are ER-positive and highly express P-Rex1 (Sosa et al., 2010). MCF-7 cells are also ErbB2positive whereas BT-474 cells are ErbB2-overexpressed. Thus, these two cell lines were chosen for our studies.
Western blot analysis showed that the P-Rex1 protein expression level in BT-474 cells is 4.5 -fold higher than that in MCF-7 cells (Fig. 1A). Thirty hours treatment with PMA caused a concentration-dependent decrease in P-Rex1 protein levels in both MCF-7 and BT-474 cells with a maximum reduction of $87.2 \% \pm 1.1 \%$ and $57.0 \% \pm 8.6 \%$, respectively, at a concentration of $10 \mathrm{ng} / \mathrm{mL}$ PMA (Fig. 1B). PMA also significantly attenuated growth of both MCF-7 and BT-474 cells in a concentration-dependent manner with an inhibition of $77.8 \% \pm 12.4 \%$ and $50.6 \% \pm 3.7 \%$, respectively, at $10 \mathrm{ng} / \mathrm{mL}$ PMA (Fig. 1C). Interestingly, PMA-induced inhibition of cell growth is correlated to the degree of P-Rex1 down-regulation in MCF-7 and BT-474 cells. Thus, a recovery assay was performed to determine whether PMA inhibition of breast cancer cell growth is P-Rex 1 dependent. As shown in Fig. 1D inset, expression of recombinant P-Rex1 restored the P-Rex1 expression level in PMA-treated MCF-7 cells. PMA treatment dramatically reduced the growth of control MCF-7 cells but not cells transfected with P-Rex1. Expression of recombinant P-Rex 1 had little effect on MCF-7 cell growth in the absence of PMA but completely restored cell growth in the presence of PMA (Fig. 1D). Although transfection of recombinant P-Rex1 plasmid only slightly increased P-Rex1 protein level in untreated BT-474 cells, it still partially restored the P-Rex1 protein expression in PMAtreated BT-474 cells (Fig. 1E, inset). More importantly, expression of recombinant P-Rex1 increased PMA-treated BT-474 cell growth by 1.7 -fold, which equals $70 \%$ of untreated control cells (Fig. 1E).

Hyperactived ErbB receptor signaling has been frequently characterized in breast carcinomas (Hynes and Lane, 2005). P-Rex1 is an essential mediator of ErbB signaling in breast cancer (Sosa et al., 2010). Thus, we silenced endogenous P-Rex 1 expression in MCF-7 and BT-474 cells by over $80 \%$ using P-Rex1 specific siRNA (Fig. $1 \mathrm{~F}$ and 1G, inset). Treatment with heregulin $(100 \mathrm{ng} / \mathrm{mL})$, an ErbB activating ligand, increased proliferation of MCF-7 (Fig. 1F) and BT-474 (Fig. 1G) cells transfected with control siRNA by 1.8 -fold and 2.1-fold respectively, as indicated by BrdU incorporation assay. However, this stimulatory effect was significantly reduced in cells transfected with P-Rex1 siRNA (Fig. 1F and 

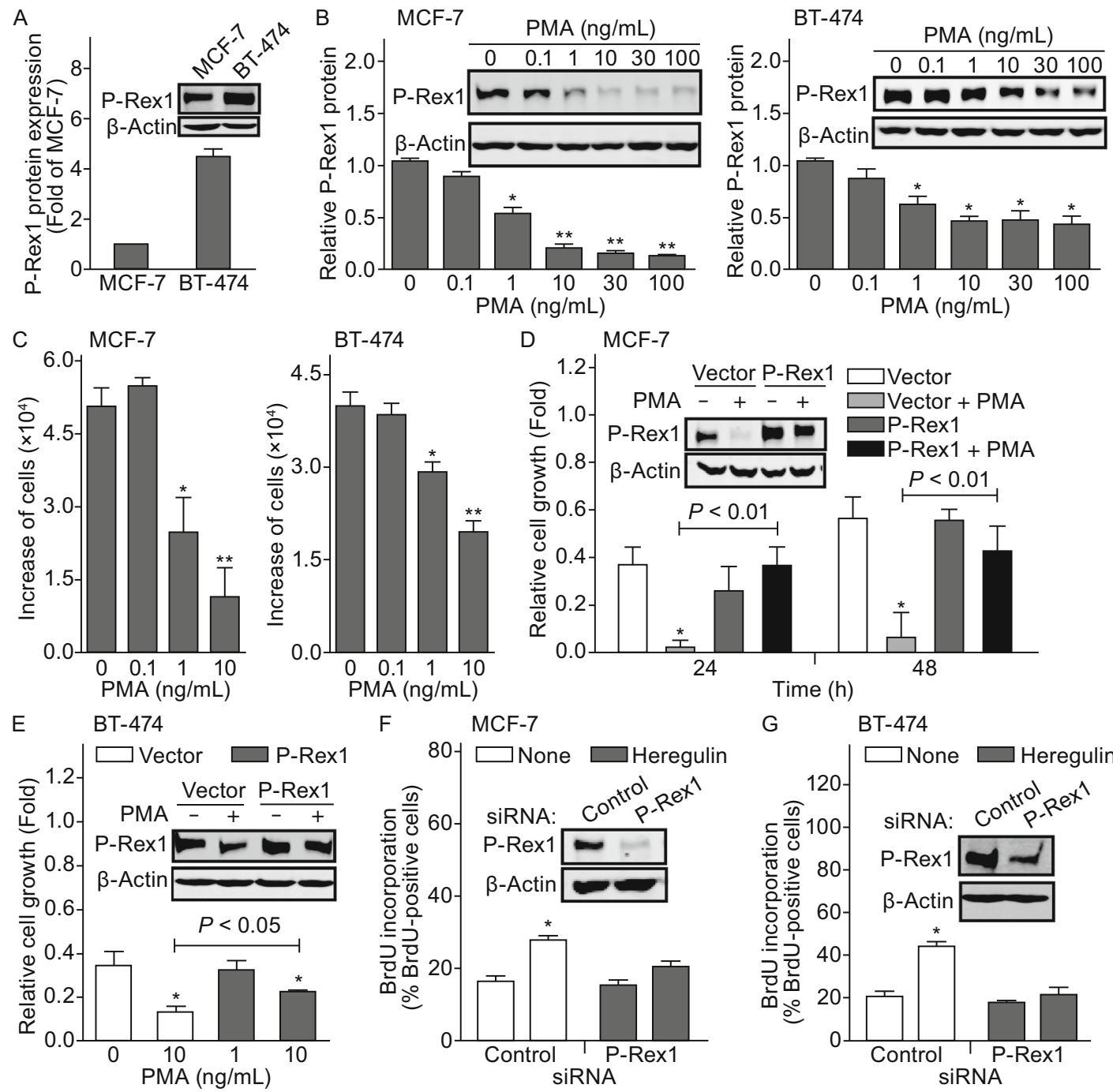

F $\quad$ MCF-7

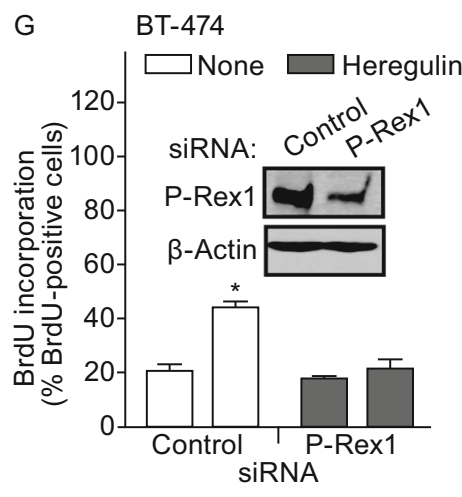

Figure 1. PMA suppresses breast cancer cell growth through P-Rex1 down-regulation. (A) Western blot analysis of P-Rex1 protein expression in MCF-7 and BT-474 cells. Data shown are means \pm SEM $(n=3)$. (B) PMA concentration-dependent downregulation of P-Rex1 protein expression in MCF-7 and BT-474 cells. Data are means \pm SEM $(n=3)$ with ${ }^{*} P<0.01$ and ${ }^{* *} P<0.001$ compared with untreated cells, normalized by $\beta$-actin. (C) PMA concentration-dependent suppression of MCF-7 and BT-474 cell growth. Cells were cultured in the presence or absence of PMA for $48 \mathrm{~h}$ (MCF-7) or $72 \mathrm{~h}$ (BT-474). Data shown are means \pm SEM $(n=$ 5 of duplicates) with ${ }^{*} P<0.05$ and ${ }^{* *} P<0.001$ as compared with untreated cells. (D and E) Expression of recombinant $P-R e x 1$ blocked PMA inhibition of MCF-7 and BT-474 cell growth. Cells transfected with control vector or P-Rex1 were cultured in the absence or presence of PMA (10 ng/mL) for $24 \mathrm{~h}$ and $48 \mathrm{~h}$ (MCF-7) or $48 \mathrm{~h}$ (BT-474). Relative cell growth refers to increased cell number normalized by cell number prior to PMA treatment. Data are means \pm SEM ( $n=5$ of duplicates) with ${ }^{*} P<0.01$ as compared to cells without PMA treatment. ( $F$ and $G$ ) Silence of endogenous P-Rex1 by its siRNA abolished heregulin (100 ng/mL)-stimulated MCF-7 and BT-474 cell proliferation, determined by BrdU incorporation assay. Data are means \pm SEM $\left(n=3\right.$ of triplicates) with ${ }^{*} P<$ 0.01 . Insets: Western blot analysis of P-Rex 1 and $\beta$-actin protein expression in MCF-7 and BT-474 cells.

1G). Together, our data suggest that P-Rex1 functions as a key molecule in breast cancer cell growth and that downregulation of P-Rex1 contributes to PMA suppression of MCF-7 and BT-474 cell growth.

PMA mimics DAG in the cellular membrane to activate $P K C$. Treatment with PMA $(10 \mathrm{ng} / \mathrm{mL})$ significantly increased
PKC kinase activity in both MCF-7 and BT-474 cells, which was completely blocked by pre-treatment with the general PKC inhibitor Gö6983 (2 $\mu \mathrm{mol} / \mathrm{L})$ (Fig. S1A). Western blot assay showed that both MCF-7 and BT-474 cells express PMA-sensitive conventional PKC isoforms ( $\alpha$ and $\beta$ ) and novel PKC isoforms $(\delta, \varepsilon$ and $\eta)$. MCF-7 cells also express 
the novel PKC isoform ( $\theta)$. In addition, PMA-insensitive atypical PKC isoforms ( $I$ and $\lambda$ ) were also detected in both MCF-7 and BT-474 cells (Fig. S1B). Immunofluorescence staining analysis showed that 30 min after treatment of MCF7 cells with PMA (10 ng/mL), PKCa appeared to translocate to the cell plasma membrane and was enriched in the nucleus whereas PKCE mainly translocated to the nucleus (Fig. S1C). These effects further indicate PKC activation upon stimulation with PMA. Interestingly, pre-treatment with Gö6983 (2 $\mu \mathrm{mol} / \mathrm{L})$ reduced the PMA inhibitory effect on P-Rex1 protein expression from $85.6 \% \pm 2.6 \%$ to $33.6 \% \pm$ $7.7 \%$ in MCF7 cells (Fig. 2A, left) and completely blocked PMA-induced down-regulation of P-Rex1 protein in BT-474 cells (Fig. 2A, right). In contrast, $100 \mathrm{nmol} / \mathrm{L}$ of Gö6976, a selective inhibitor of conventional PKC isoforms, had no effect on PMA down-regulation of P-Rex1 expression in MCF-7 and BT-474 cells (Fig. 2A). As expected, Gö6983 but not Gö6976 blocked PMA-induced suppression of MCF-7 and BT-474 cell growth (Fig. 2B). Thus, activation of novel $\mathrm{PKC}$ isoforms but not conventional $\mathrm{PKC}$ isoforms may be involved in PMA-induced P-Rex1 down-regulation and suppression of breast cancer cell growth.

It should be noted that Gö6983 is a PKC-selective but not specific inhibitor. At the concentration used $(2 \mu \mathrm{mol} / \mathrm{L})$ it also inhibits many other kinases. Our data does not exclude the possibility of involvement of other kinases in PMA effects in breast cancer cells. Thus, we investigated whether expres-

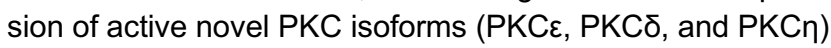
directly modulate P-Rex1 expression and breast cancer cell growth. As shown in Fig. 2C, ectopic expression of wild-type (WT) or constitutively active (CAT) PKCס or PKCn had no significant effect whereas expression of PKCE CAT mutant down-regulated $\mathrm{P}-\mathrm{Rex} 1$ protein expression in MCF-7 and BT-474 cells by $40 \%-60 \%$ (Fig. 2C). In contrast, expression of PKCE WT had no significant effect on P-Rex1 expression (Fig. 2C), suggesting that $\mathrm{PKC} \varepsilon$ overexpression by itself is not sufficient to induce P-Rex1 down-regulation in breast cancer cells. To further investigate whether PKCE activity is essential for P-Rex1 down-regulation, Gö6983 was used to inhibit the constitutively active PKCE activity. As shown in Fig. 2D, Gö6983 completely abolished PKCE CAT-induced $\mathrm{P}-\mathrm{Rex} 1$ down-regulation. Interestingly, expression of PKCE CAT mutant but not WT suppressed MCF-7 cell proliferation by $70 \%$, which was also attenuated by Gö6983 (Fig. 2E). Together, our data suggest that activation of $P K C \varepsilon$ is more important than overexpression of PKC $\varepsilon$ in regulating P-Rex1 expression and breast cancer cell growth.

In summary, our study is the first to use a small molecule, PMA, to target P-Rex1 expression levels to suppress breast cancer cell growth. PMA itself has both oncogenic and antitumorigenic properties by direct or indirect modulation of various cellular targets (Griner and Kazanietz, 2007). Previous studies suggest that induction of the cell-cycle inhibitor p21 (WAF1/CIP1) is involved in connecting the PMA-activated PKC signaling pathways to the breast cancer cell cycle regulatory machinery, leading to cell growth arrest (Barboule et al., 1999; Fortino et al., 2008). Interestingly, Rac1 was reported to be overexpressed or hyperactive in breast cancer tissues and hyperactivity of Rac1 suppressed p21 (WAF1/ CIP1) expression in cancer cells. Since P-Rex1 functions as a Rac1 activator in cancer cells, PMA-down-regulation of $\mathrm{P}-\mathrm{Rex} 1$ expression should result in reduction of Rac1 activity, leading to increased expression of p21 (WAF1/CIP1). Thus, our study provides a potential molecular mechanism underlying PMA suppression of breast cancer cell growth.

Our studies further showed that active $\mathrm{PKC} \varepsilon$, but not the other PMA-sensitive PKC isoforms, down-regulates P-Rex1 expression and suppresses breast cancer cell growth. PKCE has a unique role in regulating cell-signaling pathways in cancer (Griner et al., 2007; Urtreger et al., 2012). Elevated PKCE levels were correlated with breast cancer aggressiveness (Pan et al., 2005). Our study presents the first evidence suggesting that the PKCE/P-Rex1 pathway may be an attractive new target for therapeutic intervention, which provides an additional approach for improving the current treatment of breast cancer. For example, estrogen receptortargeted therapies have significantly reduced breast cancer mortality. However, resistance generally emerges because various growth factor receptors such as ErbB2 can transactivate estrogen receptors in an estrogen-independent manner, contributing to tumor growth. Trastuzumab, a monoclonal ErbB2 antibody, has significant clinical benefit for patients with ErbB2-elevated breast tumors (Smith et al., 2007). However, patients may also develop resistance within 1 year of treatment. A common feature of the possible mechanisms of resistance is Rac1 activation and inactivation of Rac1 reduces Trastuzumab resistance in breast cancer cells (Zhao et al., 2011). P-Rex1 is highly expressed in human breast cancers with high ErbB2 and estrogen receptor expression and functions as a Rac-specific activator at a convergence point downstream of ErbB receptors and other growth factor receptors (Montero et al., 2011; 2013; Sosa et al., 2010). Thus, it has been suggested as an attractive therapeutic target (Sosa et al., 2010). Understanding PKCE-dependent P-Rex1 down-regulation may provide a novel strategy for development of chemotherapeutic agents for P-Rex1-overexpressing breast cancer patients that develop resistance to anti-estrogen and/or antiErbB2 therapies.

\section{FOOTNOTES}

The authors thank Drs. Thomas F. Murray and Ming-Fong Lin for helpful discussion and suggestions. This work was supported, in part, by grants from US Nebraska State LB595 research program, US Department of Defense (W81XWH-13-1-0074), the National Institutes of Health (5P20GM103489), the National Basic Research Program (973 Program) (No. 2012CB934003) and the National Natural Science Foundation of China (Grant Nos. 31100595 and 31300683). This research was conducted at the Integrated Biological Imaging Facility of Creighton University, supported by National Institutes of Health grants GM103427, GM110768, and GM103427. 
A
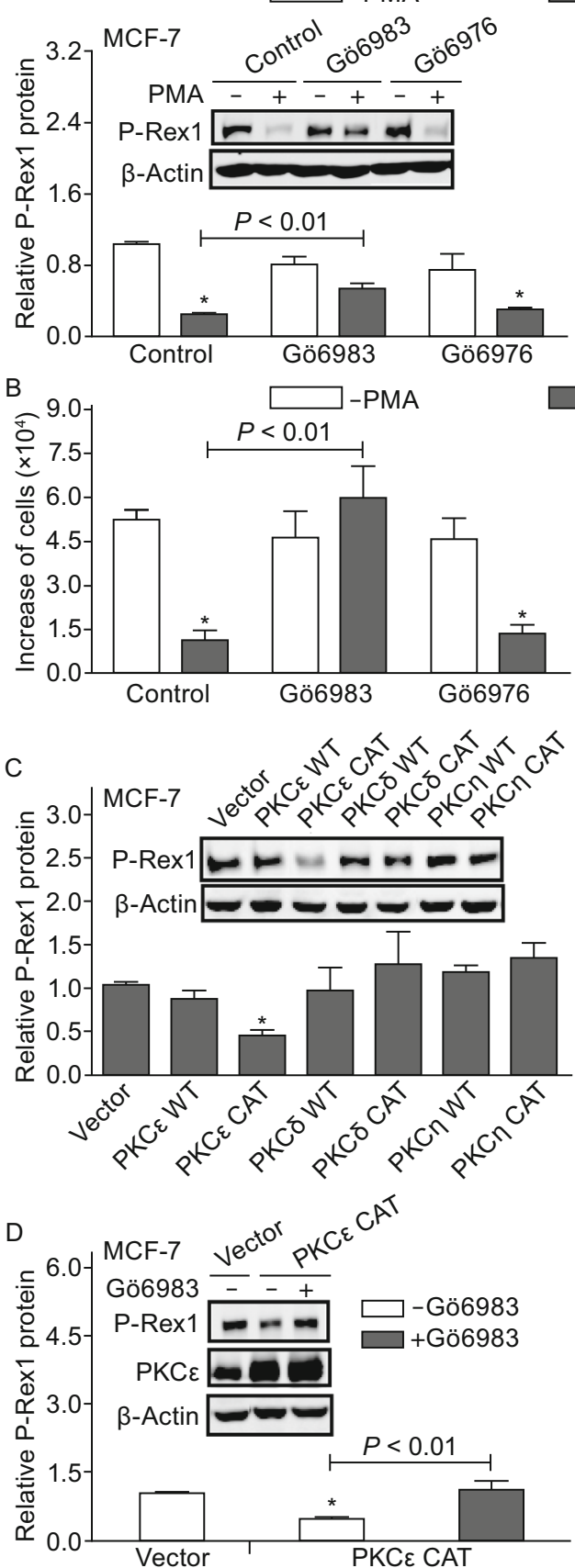

$+\mathrm{PMA}$
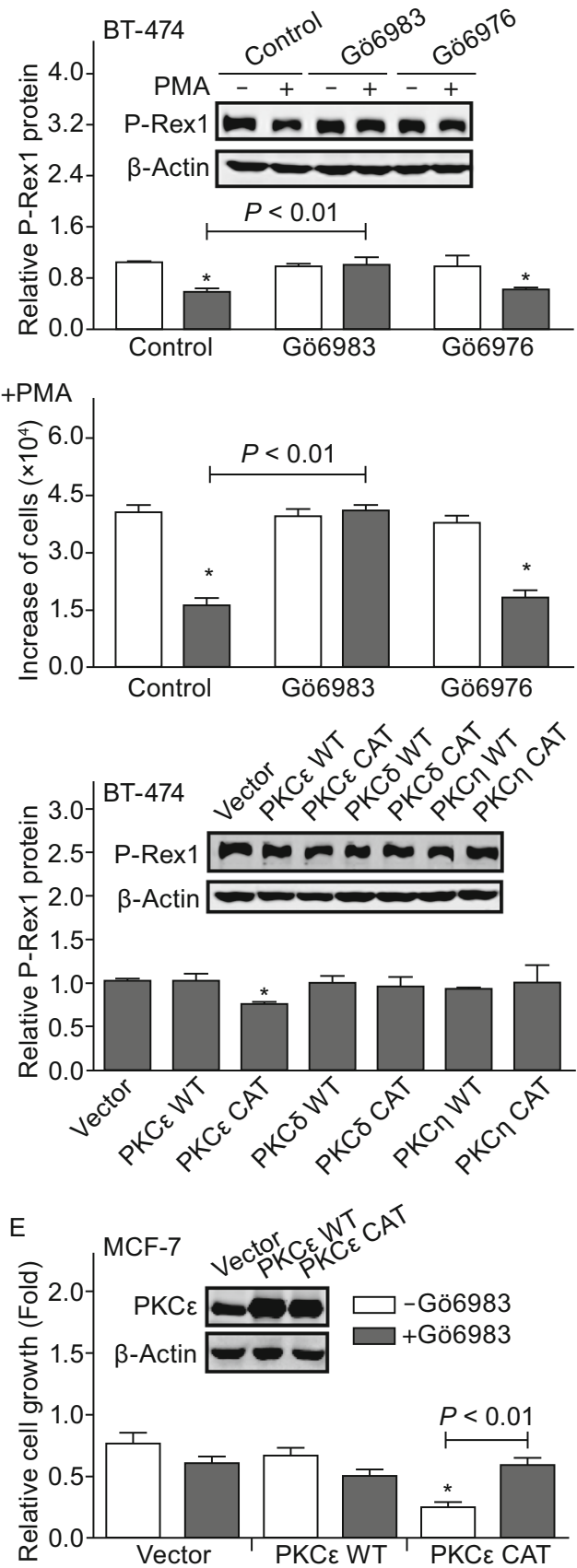

Figure 2. PKC $\varepsilon$ activation contributes to PMA suppression of breast cancer cell growth through P-Rex1 down-regulation. The general PKC inhibitor Gö6983 (2 $\mu \mathrm{mol} / \mathrm{L})$, but not the conventional PKC isoform inhibitor Gö6976 (100 nmol/L), attenuated PMA $(10 \mathrm{ng} / \mathrm{mL}$ ) suppression of P-Rex1 expression $(A)$ and breast cancer cell growth (B). (A) Western blot analysis of P-Rex1 expression. Data are means $\pm \operatorname{SEM}(n=3)$ with ${ }^{*} P<0.01$ compared to cells without PMA treatment. (B) Cell growth assay. Cells were cultured in the presence or absence of PMA for $48 \mathrm{~h}$ (MCF-7) or $72 \mathrm{~h}$ (BT-474). Data are means \pm SEM ( $n=5$ of duplicates) with ${ }^{*} P<0.01$ compared to cells without PMA treatment. (C) Expression of PKC $\varepsilon$ constitutively active form (CAT), but not PKC $\varepsilon$ wild-type (WT), PKCס or PKC $\eta$ WT and CAT mutant, down-regulated P-Rex1 expression in MCF-7 and BT-474 cells. Data are means \pm SEM $(n=3)$

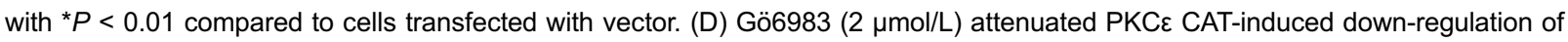
P-Rex1 expression in MCF-7 cells. (E) Expression of PKCE CAT, but not its WT, suppressed MCF-7 cell growth, which is blocked by treatment with Gö6983 (2 $\mu \mathrm{mol} / \mathrm{L})$. Data are means \pm SEM ( $n=3$ of duplicates) with ${ }^{*} P<0.01$ compared to cells transfected with vector. Insets: Representative Western blot images of P-Rex1, PKCE, and $\beta$-actin protein expression in breast cancer cells. 
Chuu-Yun A. Wong, Haihong Jiang, Peter W. Abel, Margaret A. Scofield, Yan Xie, Taotao Wei, and Yaping Tu declare that they have no conflict of interest. This article does not contain any studies with human or animal subjects performed by the any of the authors.

Chuu-Yun A. Wong ${ }^{1}$, Haihong Jiang ${ }^{1}$, Peter W. Abel ${ }^{1}$, Margaret A. Scofield ${ }^{1}$, Yan Xie ${ }^{1}$, Taotao $\mathrm{Wei}^{2 \bowtie}$, Yaping Tu ${ }^{1 凶}$

${ }^{1}$ Department of Pharmacology, Creighton University School of Medicine, Omaha, NE 68178, USA

${ }^{2}$ National Laboratory of Biomacromolecules, Institute of Biophysics, Chinese Academy of Sciences, Beijing 100101, China

$\square$ Correspondence: weitt@moon.ibp.ac.cn (T. Wei), Yat60399@creighton.edu (Y. Tu)

\section{OPEN ACCESS}

This article is distributed under the terms of the Creative Commons Attribution 4.0 International License (http://creativecommons.org/ licenses/by/4.0/), which permits unrestricted use, distribution, and reproduction in any medium, provided you give appropriate credit to the original author(s) and the source, provide a link to the Creative Commons license, and indicate if changes were made.

\section{REFERENCES}

Barboule N, Lafon C, Chadebech P, Vidal S, Valette A (1999) Involvement of p21 in the PKC-induced regulation of the G2/M cell cycle transition. FEBS Lett 444:32-37

Fortino V, Torricelli C, Capurro E, Sacchi G, Valacchi G, Maioli E (2008) Antiproliferative and survival properties of PMA in MCF-7 breast cancer cell. Cancer Invest 26:13-21

Griner EM, Kazanietz MG (2007) Protein kinase C and other diacylglycerol effectors in cancer. Nat Rev 7:281-294

Hynes NE, Lane HA (2005) ERBB receptors and cancer: the complexity of targeted inhibitors. Nat Rev Cancer 5:341-354

Knight-Krajewski S, Welsh CF, Liu Y, Lyons LS, Faysal JM, Yang ES, Burnstein KL (2004) Deregulation of the Rho GTPase, Rac1, suppresses cyclin-dependent kinase inhibitor p21 (CIP1) levels in androgen-independent human prostate cancer cells. Oncogene 23:5513-5522
Montero JC, Seoane S, Ocaña A, Pandiella A (2011) P-Rex1 participates in Neuregulin-ErbB signal transduction and its expression correlates with patient outcome in breast cancer. Oncogene 30:1059-1071

Montero JC, Seoane S, Pandiella A (2013) Phosphorylation of P-Rex1 at serine 1169 participates in IGF-1R signaling in breast cancer cells. Cell Signal 25:2281-2289

Pan Q, Bao LW, Kleer CG, Sabel MS, Griffith KA, Teknos TN, Merajver SD (2005) Protein kinase $C$ epsilon is a predictive biomarker of aggressive breast cancer and a validated target for RNA interference anticancer therapy. Cancer Res 65:8366-8371

Qin J, Xie Y, Wang B, Hoshino M, Wolff DW, Zhao J, Scofield MA, Dowd FJ, Lin MF, Tu Y (2009) Upregulation of PIP3-dependent Rac exchanger 1 (P-Rex1) promotes prostate cancer metastasis. Oncogene 28:1853-1863

Schnelzer A, Prechtel D, Knaus U, Dehne K, Gerhard M, Graeff H, Harbeck N, Schmitt M, Lengyel E (2000) Rac1 in human breast cancer: overexpression, mutation analysis, and characterization of a new isoform, Rac1b. Oncogene 19:3013-3020

Smith M, Procter RD, Gelber S, Guillaume A, Feyereislova M, Dowsett A, Goldhirsch M, Untch G, Mariani J, Baselga J et al (2007) 2-year follow-up of trastuzumab after adjuvant chemotherapy in HER2-positive breast cancer: a randomised controlled trial. Lancet 369:29-36

Sosa MS, Lopez-Haber C, Yang C, Wang H, Lemmon MA, Busillo JM, Luo J, Benovic JL, Klein-Szanto A, Yagi H et al (2010) Identification of the Rac-GEF P-Rex1 as an essential mediator of ErbB signaling in breast cancer. Mol Cell 40:877-892

Urtreger AJ, Kazanietz MG, de Kier Bal, Joffé ED (2012) Contribution of individual PKC isoforms to breast cancer progression. IUBMB Life 64:18-26

Welch HC, Coadwell WJ, Ellson CD, Ferguson GJ, Andrews SR, Erdjument-Bromage $\mathrm{H}$, Tempst $\mathrm{P}$, Hawkins PT, Stephens LR (2002) P-Rex1, a Ptdlns(3,4,5)P3- and Gbetagamma-regulated guanine-nucleotide exchange factor for Rac. Cell 108:809-821

Zhao Y, Wang Z, Jiang Y, Yang C (2011) Inactivation of Rac1 reduces Trastuzumab resistance in PTEN deficient and insulinlike growth factor I receptor overexpressing human breast cancer SKBR3 cells. Cancer Lett 313:54-63

Electronic supplementary material The online version of this article (doi:10.1007/s13238-016-0261-x) contains supplementary material, which is available to authorized users. 